\title{
Palliative care subspecialty in the offing
}

A

$\mathrm{n}$ aging population, a tide of chronic disease and spotty access to quality end-of-life care makes the establishment of palliative medicine as a subspecialty, and certification of family physicians with added competence in palliative medicine, logical steps in the provision of care to Canadians, experts contend.

Now in the offing, the changes will ultimately result in bolstered capacity to serve societal needs, says Dr. Cori Schroder, cochair of the Royal College of Physicians and Surgeons of Canada and the College of Family Physicians of Canada Conjoint Advisory Committee on Palliative Medicine. "I think the bottom line is that this is going to promote more accessible and more complete care for a broadening patient population."

A two-year subspecialty program in palliative medicine is currently under consideration for approval by the Royal College of Physicians and Surgeons of Canada, while the College of Family Physicians of Canada is drafting the criteria under which a certificate of added competence in palliative medicine should be awarded.

The growing number of elderly patients with chronic conditions and expanding demand for palliative care has spurred calls for more training of physicians in end-of-life care (www.cmaj .ca/lookup/doi/10.1503/cmaj.109-4223).

Studies have also indicated that access to high-quality end-of-life care varies substantially across the nation (www.cmaj .ca/lookup/doi/10.1503/cmaj.109-3763).

Creation of a subspecialty and certification of family doctors with competence in the provision of palliative care, in tandem, would be a definite boon to the delivery of palliative care in Canada, says Dr. Sandy Buchman, president of the College of Family Physicians of Canada. There is a need for physicians with expertise or enhanced skills in palliative medicine, particularly when it comes to the handling of patients with complex combinations of diseases, he explains.

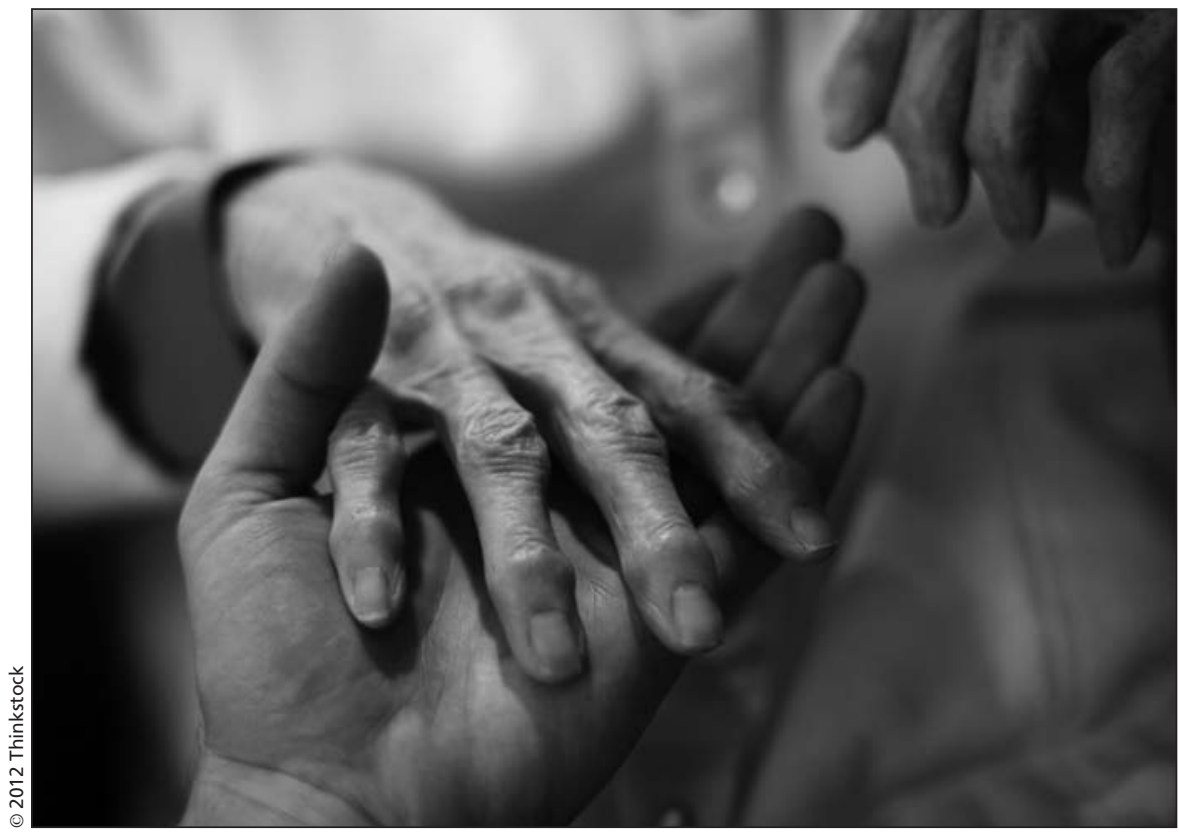

An aging population and a tide of chronic disease mean more Canadians need a helping hand, leading to increased demand for palliative care services and expertise.

Moreover, history suggests that advances in the provision of a service such as palliative medicine require such specialization and certification, says Dr. Joshua Shadd, an assistant professor in the Department of Family Medicine at the Schulich School of Medicine \& Dentistry at Western University in London, Ontario. "The generalist can't be expected to advance the field."

While a one-year program of added competence in palliative medicine jointly accredited by the Royal College of Physicians and Surgeons of Canada and the College of Family Physicians of Canada has been offered by various Canadian medical schools since 1999, it has not resulted in specialist recognition or any manner of certification.

The proposed two-year subspecialty, by contrast, will result in recognition, Dr. Deborah Dudgeon, cochair of the conjoint advisory committee, writes in an email. Admittance to palliative subspecialty training would typically follow completion of specialty training in internal medicine, neurology, anaesthe- sia or pediatrics but a practice-eligible route is also under consideration, though the parameters have yet to be defined, she adds.

It's expected that subspecialty training will consist of two streams adult and pediatric - that would aim to equip physicians with such core competencies as the ability to assess and manage pain and to address psychological, social, spiritual and existential issues that might arise when treating patients.

Meanwhile, certification of family doctors with added competence in palliative care being hashed out by the College of Family Physicians of Canada is part of a move to bring the growing number of physicians with special interests (www.cmaj.ca/lookup/doi/10.1503 /cmaj.109-4040) back into the fold of comprehensive care (www.cmaj.ca /lookup/doi/10.1503/cmaj.109-4036). In June, the college's board of directors approved the development of criteria for the awarding of a certificate of added competence with or without a special designation in palliative care, sport and 
exercise medicine, anaesthesia, emergency medicine and care of the elderly (www.bccfp.bc.ca/Highlights_CFPC\%20 Board\%20of\%20Directors\%20Meeting \%20June\%202012.pdf).

Currently, emergency medicine is the only branch allowed special designation by the College of Family Physicians of Canada.

Buchman says such a designation would be beneficial as it would allow for greater recognition of family doctors who do extra studies and work in the area of palliative medicine. But the risk is that this move may unintention- ally communicate to graduating family physicians that additional certification is required to be competent to provide such palliative services, he adds. "We don't want to give that message at all."

Some issues still need to be ironed out in the creation of a subspecialty of palliative medicine and certification of family doctors with expertise in the area, notes Dr. Doris Barwich, president of the Canadian Society of Palliative Care Physicians.

It had been hoped that a subspecialty could be created that would be accessible from both the Royal College of Physicians and Surgeons of Canada and College of Family Physicians of Canada streams but that didn't pan out because of the colleges' disparate missions, Barwich says, adding that care will be required going forward to prevent a two-tiered outcome. "Our history is that we've been able to do this collaboratively and jointly, but now that both colleges are defining a different way forward, there's work for us to do to make sure that doesn't split the profession." - Michael Monette, CMAJ

CMAJ 2012. DOI:10.1503/cmaj.109-4255 